\title{
Rattle Detection - An Automotive Case Study
}

\author{
Orla Hartley CEng MEng APMA MIET, \\ Jaguar Land Rover, UK (orlamurphyhartley@gmail.com)
}

Purpose: This paper is a case study showcasing the use of statistical tools to develop an objective Squeak and Rattle (S\&R) measurement detection test for End Of Line (EOL) sign off in an automotive manufacturing environment.

Methodology / Approach: This case study shows how statistical tools from Six Sigma methodology were utilised in an industrial application at an Automotive Manufacturer. An objective measurement system was developed. A structured process was followed to complete a Design of Experiment (DOE). A pilot study was completed to help implement the objective measurement system for Audio Induced Squeak and Rattle.

Findings: This case study showcases a practical application of a Design of Experiment to optimise the parameters of the testing equipment required for an objective rattle test. The optimal parameters were defined as a 90dB input frequency sweep for 5 seconds duration. The analysis of the main effects plot found that the length of time had a minimal effect on the dependent variable $\mathrm{dB}$, but that the volume of the input sweep had a much larger effect. A pilot study showed the objective test did highlight rattles to the operators and could help identify producer risk and customer risk. Ultimately, the subjective test for detecting rattle was replaced with a more robust objective test.

Research Limitations/ Implications: This research is limited to one vehicle manufacturers implementation of an objective S\&R detection process.

Keywords: Design of Experiment, Squeak and Rattle, objective testing, test optimisation, measurement system development, automotive case study, Six Sigma

Paper Type: Case Study 


\section{$8^{\text {th }}$ INTERNATIONAL CONFERENCE ON LEAN SIX SIGMA}

\section{Introduction}

Audio Induced Squeak and Rattle (S\&R) is a quality concern, with customers regularly requesting repairs for any noise causing them annoyance. It impacts on perception of vehicle quality [1] [2]. Improvements to Audio Induced S\&R can be engineered in a variety of ways, for example by Computer Aided Engineering or speaker fixing durability studies. This paper focuses on a project to introduce an objective End Of Line (EOL) test in the manufacturing plant. The EOL test is the final check for rattles and is the last opportunity for the manufacturer to prevent plant escapes. The warranty data analysed indicated customer complaints were early in the vehicle life, indicating that plant escapes were a key concern.

The existing EOL test for audio induced rattles was a subjective listening test, where the operator listened for rattles induced by the sound system. The process involved operators listening to a set list of audio tracks and indicating if any rattles were present. This test was leading to bottlenecks, rework, disruption and warranty, as well as time wasted in debate between operators and supervisors about the agreed conditions of vehicle rattles. The average time to rework a failed vehicle was 85 minutes, causing massive disruption to the overall assembly process of the vehicle.

The early phases of the project developed an objective test using microphones and analysers. The equipment utilised was the Klippel Quality Control system [3]. Studies were carried out to investigate the Repeatability and Reproducibility (R\&R) of the subjective and objective tests using a Gauge R\&R approach. Unsurprisingly, the results for repeatability were found to be unsatisfactory for a subjective test with measurement error of $30 \%$. There was a large improvement in both repeatability and reproducibility for the objective test which had only $2 \%$ error [4]. Subsequent phases of the project investigated variability between vehicles and carried out a pilot study for statistical analysis, comparison and improvements [5].

This case study paper gives an overview to the statistical tools used during this project to develop an objective S\&R detection test for the EOL. The case study details the measurement system development, a design of experiment (DOE) to optimise the test parameters, and the pilot study of the new test. These three are detailed because they were found to be the most influential to the development, implementation and acceptance of the EOL test in the manufacturing plant.

Other published contributions to the S\&R field focus broadly on topics such as rattle detection, analysis, mechanisms or characterisation. This paper is novel in that it focuses on a practical application of tools to tackle plant escapes of rattles. Secondly, the replacement of a subjective test with an objective one can also be more broadly applied to many industries and processes.

The outline of this paper is as follows. This chapter described the background, scope and applications of the case study. Chapter 2 describes the methodology, including the planning, design, and execution of the Design of Experiment (DOE). Chapter 3 outlines the key results and analysis. Chapter 4 includes a summary of the conclusions and future recommendations.

\section{Methodology}

This case study is based off an internal Black Belt Six Sigma project at a premium automotive manufacturer. Different aspects of the project were split down into sub projects, 


\section{$8^{\text {th }}$ INTERNATIONAL CONFERENCE ON LEAN SIX SIGMA}

which followed Define, Measure, Analyse, Improve and Control (DMAIC) methodology. Table 1 summarises some of the tools used in the project for each DMAIC stage with a rationale for why they were useful. This case study will not detail the entire project, instead it will give an overview to the overall measurement system development, DOE and pilot study. These three were chosen for the case study as they had the most influence on the implementation and acceptance of the new objective test.

\begin{tabular}{|c|c|c|}
\hline $\begin{array}{l}\text { DMAIC } \\
\text { phase }\end{array}$ & Tools Utilised & Rationale / Further Details \\
\hline Define & $\begin{array}{l}\text { Process Mapping: } \\
\text { Process (Gemba) } \\
\text { Walk, Spaghetti } \\
\text { Diagrams, Value } \\
\text { Stream Mapping } \\
\text { (VSM) }\end{array}$ & $\begin{array}{l}\text { Understanding S\&R testing in the plant. The VSM } \\
\text { was useful to document the rework process for } \\
\text { failed vehicles. }\end{array}$ \\
\hline Define & Fishbone Analysis & $\begin{array}{l}\text { To detail all the potential root causes for } \mathrm{S} \& \mathrm{R} \\
\text { customer issues. To highlight the subjective } \\
\text { listening test as the primary escape point for the } \\
\text { project. }\end{array}$ \\
\hline Define & $\begin{array}{l}\text { Warranty Data } \\
\text { Analysis }\end{array}$ & $\begin{array}{l}\text { To identify which manufacturing plant and which } \\
\text { carline to complete the DOE and pilot study on. }\end{array}$ \\
\hline Measure & Gauge R\&R & $\begin{array}{l}\text { Understanding the repeatability and reproducibility } \\
\text { of the existing subjective and proposed objective } \\
\text { test. }\end{array}$ \\
\hline Measure & $\begin{array}{l}\text { Factor Screening } \\
\text { Experiment }\end{array}$ & $\begin{array}{l}\text { Investigation of appropriate factors and levels for } \\
\text { the inference space of the DOE }\end{array}$ \\
\hline $\begin{array}{l}\text { Measure \& } \\
\text { Analyse }\end{array}$ & $\begin{array}{l}\text { Design of Experiment } \\
\text { (DOE) }\end{array}$ & $\begin{array}{l}\text { Used to optimise and finalise the factor parameters } \\
\text { within the test equipment. }\end{array}$ \\
\hline Analyse & $\begin{array}{l}\text { Data Processing - } \\
\text { Matlab }\end{array}$ & $\begin{array}{l}\text { Post processing of the collected rattle data to } \\
\text { establish the response variable for further statistical } \\
\text { analysis. }\end{array}$ \\
\hline Analyse & Residual Plots & $\begin{array}{l}\text { Check for violation of assumptions for the reduced } \\
\text { model. }\end{array}$ \\
\hline Analyse & $\begin{array}{l}\text { Response Surface } \\
\text { Plots }\end{array}$ & Graphically analysing the reduced model terms. \\
\hline
\end{tabular}


$8^{\text {th }}$ INTERNATIONAL CONFERENCE ON LEAN SIX SIGMA

\begin{tabular}{|c|c|c|}
\hline Analyse & Main Effects Plot & $\begin{array}{l}\text { Determining the optimal settings for factors to } \\
\text { finalise the measurement system for } \\
\text { implementation. }\end{array}$ \\
\hline Analyse & Regression Analysis & $\begin{array}{l}\text { Analysis of the main effects within the reduced } \\
\text { model, establish model error, understanding P- } \\
\text { values and interactions. Estimating the Prediction } \\
\text { Equation. }\end{array}$ \\
\hline Analyse & Process Capability & $\begin{array}{l}\text { Measurement system capability analysis, including } \\
\text { operator training and operational definition were } \\
\text { completed. }\end{array}$ \\
\hline Improve & $\begin{array}{l}\text { Spaghetti Diagrams } \\
\text { and Process Maps }\end{array}$ & $\begin{array}{l}\text { Outline and optimise how the new process is to be } \\
\text { implemented at the EOL }\end{array}$ \\
\hline Improve & Pilot Study & $\begin{array}{l}\text { Validate the measurement system and calculate } \\
\text { pass-fail limits for implementation }\end{array}$ \\
\hline Improve & $\begin{array}{l}\text { Failure Mode Effects } \\
\text { Analysis (FMEA) }\end{array}$ & $\begin{array}{l}\text { Outline, eliminate or reduce failures or variability to } \\
\text { do with the new EOL S\&R test. }\end{array}$ \\
\hline Control & Work Element Sheet & $\begin{array}{l}\text { Detailed description of how to carry out new } \\
\text { process. Included all documentation for process } \\
\text { handover to Manufacturing }\end{array}$ \\
\hline
\end{tabular}

Table 1: DMAIC Phases, Tools Utilised and Rationale for Use

\subsection{Measurement System Development and Analysis}

Early in the project, following the fishbone analysis, process mapping and warranty data analysis, it was concluded that the subjective listening test at the EOL was a key escape point for S\&R. The internal Black Belt project was scoped around replacing the subjective test with an objective test. The objective measurement system for S\&R was developed using the Klippel Quality Control system [3]. This consisted of an internal microphone placed over the rear-view mirror, an external microphone placed outside the vehicle and an input signal connection from the analyser to the vehicle through the Auxiliary input. The internal and external microphone setup in the vehicle can be seen in Figure 1. 


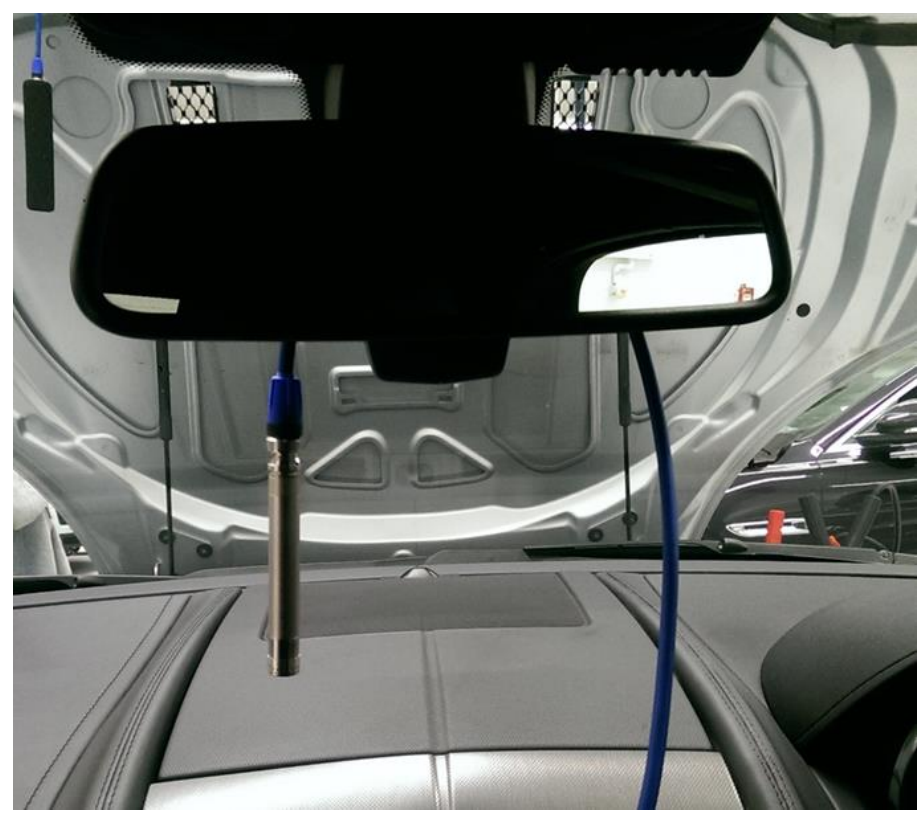

Figure 1: Klippel Equipment in Vehicle, Showing the Internal and External Microphone

The test sends a frequency sweep from the analyser to the vehicle speakers. The internal microphone records the resulting sound within the cabin, which includes both the signal sent and any additional audio induced S\&R. The system cancels out the signal that was sent and this results in the analyser outputting a frequency graph of calculated rattle. The external microphone cancels out external noise and can signal for a rerun if the test is interrupted by noise in the manufacturing environment.

A rattle event consists of unwanted vibration at a certain frequency. The frequency measured by the objective measurement system has an added benefit in that it helps to locate the source of the audio induced S\&R event, reducing problem solving and rework times. For example, a high frequency rattle will indicate that a tweeter is the likely source, or a low frequency rattle indicates a woofer is the probable source. Another benefit is that as detailed measurements are taken of different vehicles and sound systems, a database of rattles and vehicle specifications can be collected which can then be used for future problem solving, systemic rattle design changes or assembly process improvements.

Rattles are observed as a peak in the objective measurements above the general measurement trend line. The frequency response in Figure 2 highlights the rattle with a purple triangle above a peak in the trendline. The graphs output from the measurement equipment can be visually inspected at the EOL to support a pass or fail decision, and pass or fail limits for EP can also be set to further increase objectivity.

It is challenging to compare two graphs robustly. Both Matlab and Minitab were thus utilised to post process the data and extract a single measurement for the height of the largest rattle from each measurement [6]. Matlab software scripts were written to extract the maximum height for the rattle events above the trendline, named the "Event Prominence" (EP). This is a calculation of the highest rattle artefact detected in each measurement, indicated by purple triangles in Figure 2. Trialling the software at the EOL indicated that subjectively passed vehicles with no rattles had very small EP measurements, but vehicles with a rattle had a 


\section{$8^{\text {th }}$ INTERNATIONAL CONFERENCE ON LEAN SIX SIGMA}

larger EP. A graph for a typical pass and a typical fail is included in Figure 2. The EP measurement is indicated by a purple triangle in both graphs.
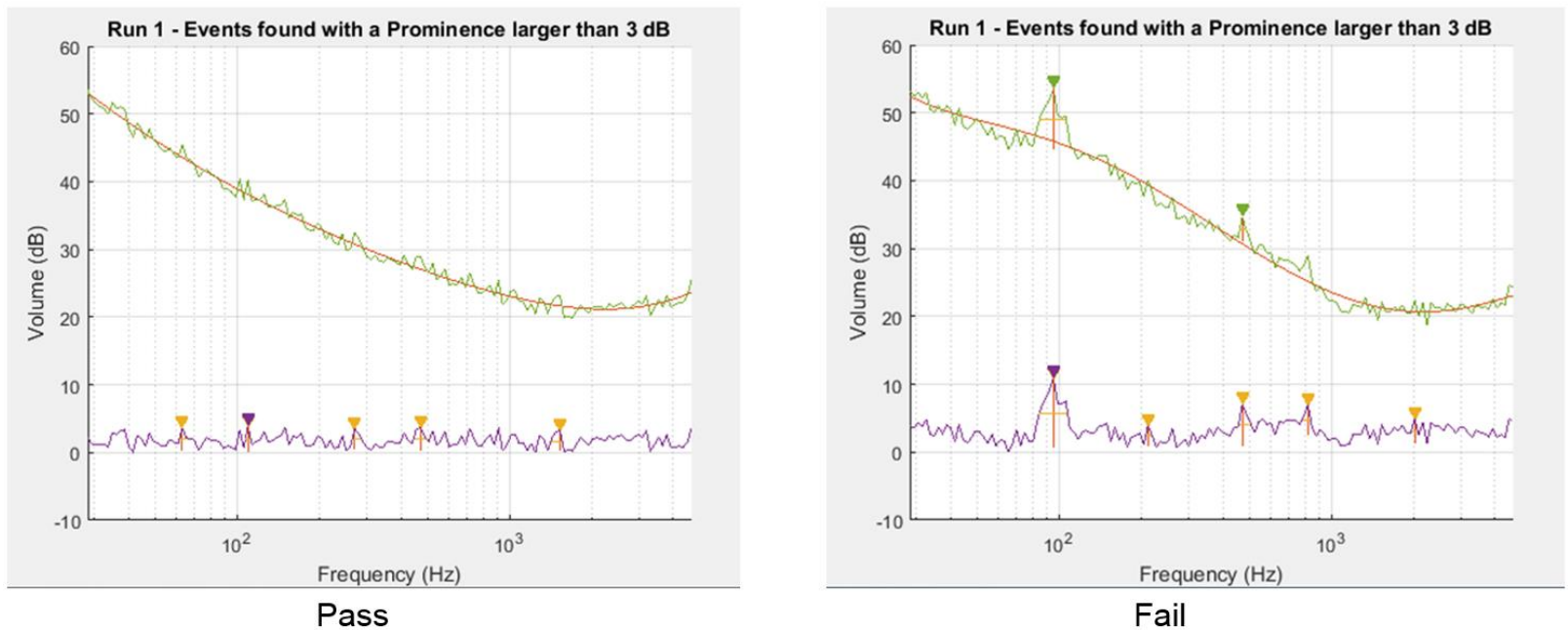

Figure 2: Matlab Analysis Showing the Extent of the Rattle ("Event Prominence") for a Typical Pass and Fail Vehicle.

The measurement system development included studies across multiple vehicle types and sound systems. The existing subjective test was found to have $30 \%$ error because of operator subjectivity. This subjectivity is eliminated with an objective measurement system. Small variation does exist with this system, for example as a result of where the microphone is placed inside the vehicle. A Gauge R\&R was completed on the objective test with the Event Prominence as the response variable and this proved the measurement system was $98 \%$ repeatable and reproducible with only $2 \%$ error. Thus, a trustworthy Measurement System Analysis (MSA) was established which was a major success of the project.

\subsection{Design of Experiment (DOE) Methodology}

Planning, designing, executing and validating the DOE followed a structured process [7]. The scope of the DOE was to optimise the only two editable parameters of the measurement test signal; time (measured in seconds) and the volume (measured in $\mathrm{dB}$ ). The parameters influenced the EP output measurement and needed to be optimised and set for implementation of the test at the EOL. The goal was to maximise the EP measurement when a rattle was truly present in the vehicle, but not to fail vehicles that do not have a rattle.

One challenge to designing the DOE was that rattles are unique to an individual vehicle, for example based on small variabilities in how the vehicle was assembled. An additional challenge is that rattles are intermittent, for example when doors are opened and closed the condition of a rattle can alter [8]. To overcome these constraints, the DoE was carried out on a single vehicle with a clear rattle. This was possible as the factors were in software, allowing the factor levels to be altered for each run without changing the condition of the rattle in the vehicle or moving the microphones. Therefore, it was possible to analyse how the EP for a specific rattle changed when the length of the input sweep changed, or the volume changed. This greatly reduced variability within the DOE. 


\section{$8^{\text {th }}$ INTERNATIONAL CONFERENCE ON LEAN SIX SIGMA}

A DOE is used to understand how varying the different factors will impact the output variable (in this case the detected rattle "EP") and to understand if there were any interactions between the factors of the DOE. A Response Surface Methodology (RSM) approach was chosen to optimise and maximise the EP seen by the operators in the measurements at the EOL [7], to ensure any rattles were clearly visible and could be seen above the baseline frequency response. It was also the approach chosen to see if there was any curvature in the response surface.

An inference screening experiment run using the equipment at the EOL for several weeks resulted in the factor inference space being set to 1-20 seconds for time and 78-90dB for volume. This space incorporated the parameters which could impact the EP, for example volumes below $78 \mathrm{~dB}$ did not highlight a significant EP above the frequency trendline and so was too quiet to stimulate the rattles. It was theorised that this inference space would incorporate the full spectrum of suitable parameters and thus would include the optimal settings for time and volume which would optimise EP. A graph showing the RSM input points is shown in Figure 3.

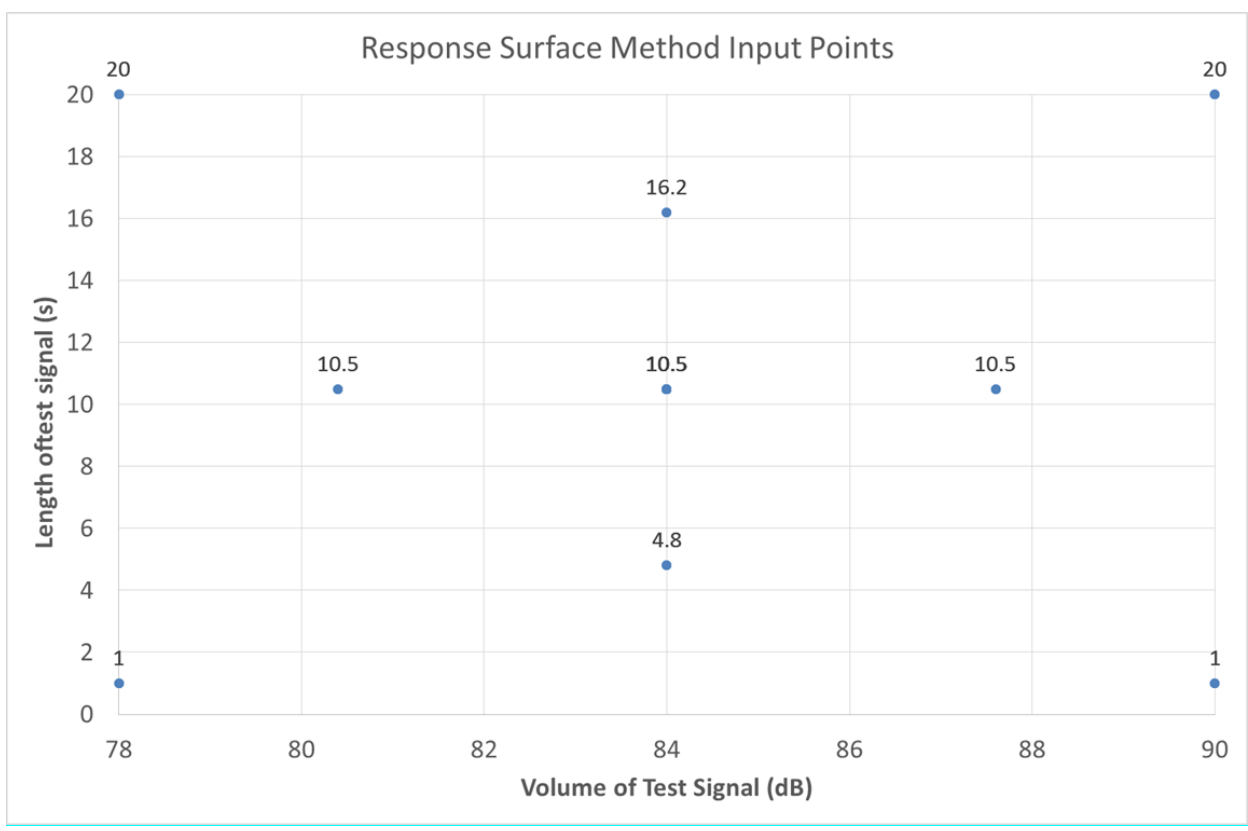

Figure 3: Response Surface Methods Input Points for Two Factors

The RSM had a Central Composite design which works by repeating the central point measurement across many of the runs to get an idea of variation at that point, and then applying an estimation of variation at the other points in the RSM [9] [10]. Alpha was set to 0.6, which determined the length of the arms of the "plus" sign from the Central Composite. This was chosen to identify if there was any response curvature within the inference space. The experiment design was created in Minitab. Random order was utilised to spread the effects of noise variables [11]. As outlined in Figure 4, the DOE had 26 randomised runs. The response variable EP was captured for each run of the DOE. Thus, the DOE scrutinised the height of the EP peak with changing levels of the two factors. 


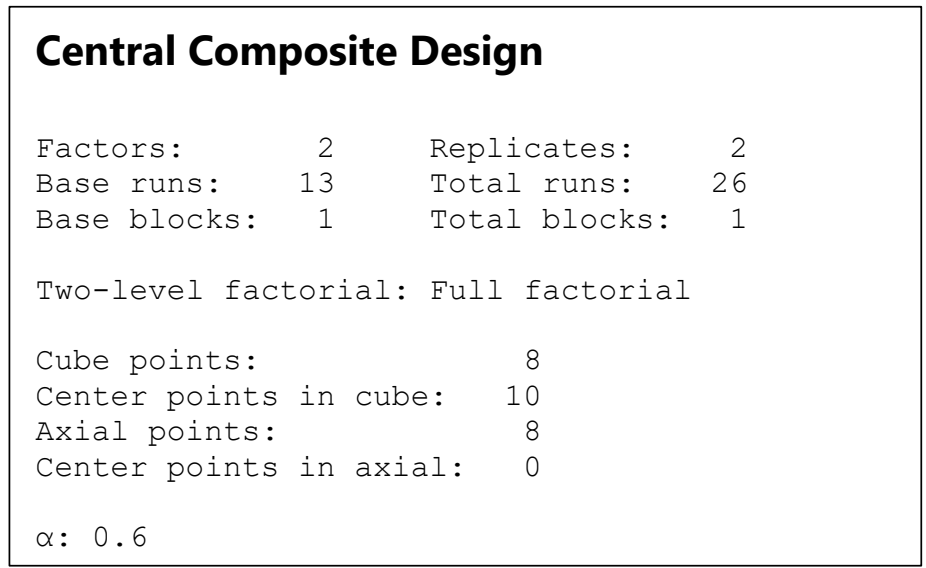

Figure 4: Minitab Session Showing Central Composite Design Elements

\subsection{Pilot Study}

A pilot study was carried out to trial the settings chosen from the DOE on the measurement system developed for detecting S\&R. Additionally, the pilot allowed further analysis to compare the existing subjective test with the proposed objective test. Operators with experience of the existing subjective listening test were recruited and trained to carry out the pilot. The pilot focussed on one sound system within one vehicle line. 16 production vehicles were included in the study. Five objective measurements were taken on each vehicle to capture any variability "within" the car itself. This variability could be because of the changing condition of the rattle. A study carried out prior to the pilot showed that the variability in the objective measurements were primarily as a result of the changing conditions of the rattle, with only $2 \%$ of variability caused by the measurement equipment. A boxplot was created showing the sample mean, median, and interquartile boxes. It was an assumption initially that "Passed" cars would have low event prominence compared to "Failed" Cars, but this is the graph required to see if this assumption was correct.

\section{Results and Discussion}

\subsection{Design of Experiment}

The results of the DOE were modelled through a regression analysis approach. The model was reduced to include only terms with low P-values. A low P-value indicates that changes in the factors are related to changes in the response variable [6]. Removing high P-value terms eliminated insignificant factors that add noise to the model. The model was considered to be fully reduced when all p-values were less than 0.05 and all Variance Inflation Factors (VIF) are lower than 2 [12] [13].

The full ANOVA included both Volume (Called factor "A" in Minitab) and Time ("B") as well as combinations of these factors. The full model showed a very high $\mathrm{P}$-value for $\mathrm{A}^{*} \mathrm{~A}$ and $\mathrm{B} * \mathrm{~B}$. The corresponding Variation Inflation Factors (VIF) were also too high. To reduce the model the high order terms can be deleted one at a time, and the model is re-run. This is repeated until the model is fully reduced and all P-Values and VIFs are in a suitable range [14]. The final model included only factors of Volume and Time and had an R-squared predictive value of $98.4 \%$. 
The next stage of the DOE was to graphically analyse the model. The response surface plots are shown in Figure 5 and Figure 6. These indicated the response was $1^{\text {st }}$ order with a very small twist. They indicate the volume has a large impact on the response variable EP compared to time. This is clearly observed in the Main Effects plot in Figure 7. This was interesting as it was assumed that time would have a larger impact, with longer time potentially liberating more rattles in the vehicle, but this was not the case.

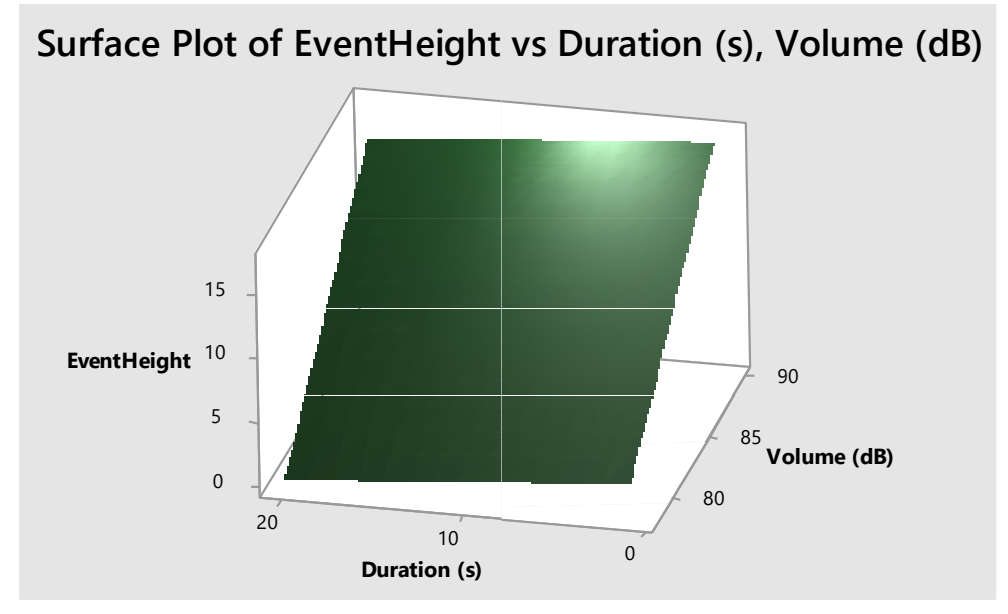

Figure 5: Surface Plot of Event Prominence against Duration and Volume (Alternative Angle)

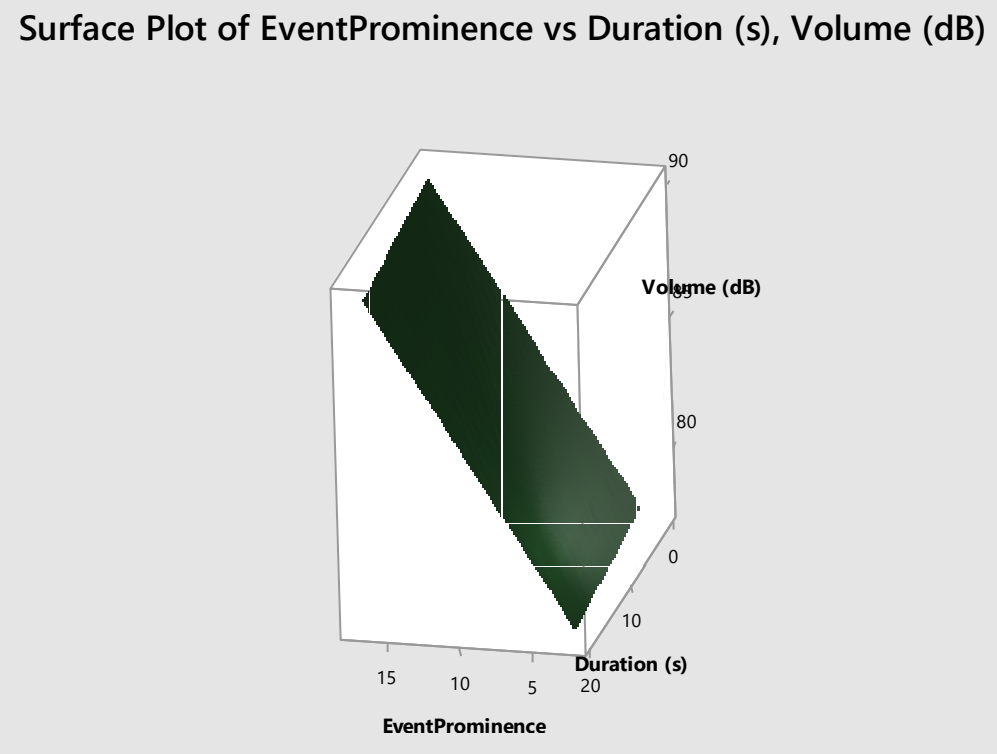

Figure 6: Surface Plot of Event Prominence against Duration and Volume 


\section{$8^{\text {th }}$ INTERNATIONAL CONFERENCE ON LEAN SIX SIGMA}

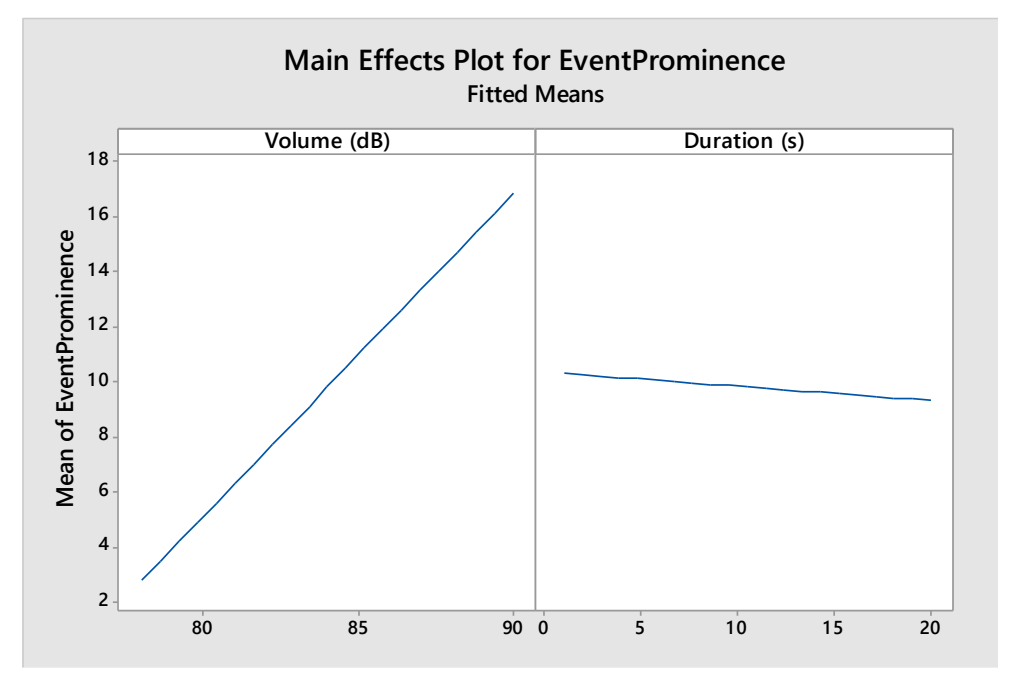

Figure 7: Main Effects Plot for Event Prominence

As the surface response was flat there was no clear combination of factors that stood out as an optimised combination. It did identify that the test time could be shortened. The settings chosen for the pilot study of the DOE were a volume of $90 \mathrm{~dB}$ and a time of 5 seconds. $90 \mathrm{~dB}$ was chosen as it corresponds to a larger and more noticeable EP on the graphs at the EOL, without introducing distortion. 5 seconds was chosen as it was long enough to ensure the operators could hear the test when standing outside of the vehicle.

The next stage of the DOE was to calculate the percentage of variation explained by each term. Reducing the model identified how much variation was explained by the mathematical model and how much was not explained, known as the model error [15]. The Sequence Sum of Squares ("SS") was used to analyse this. Figure 8 analyses the SS and explains that $98.4 \%$ 


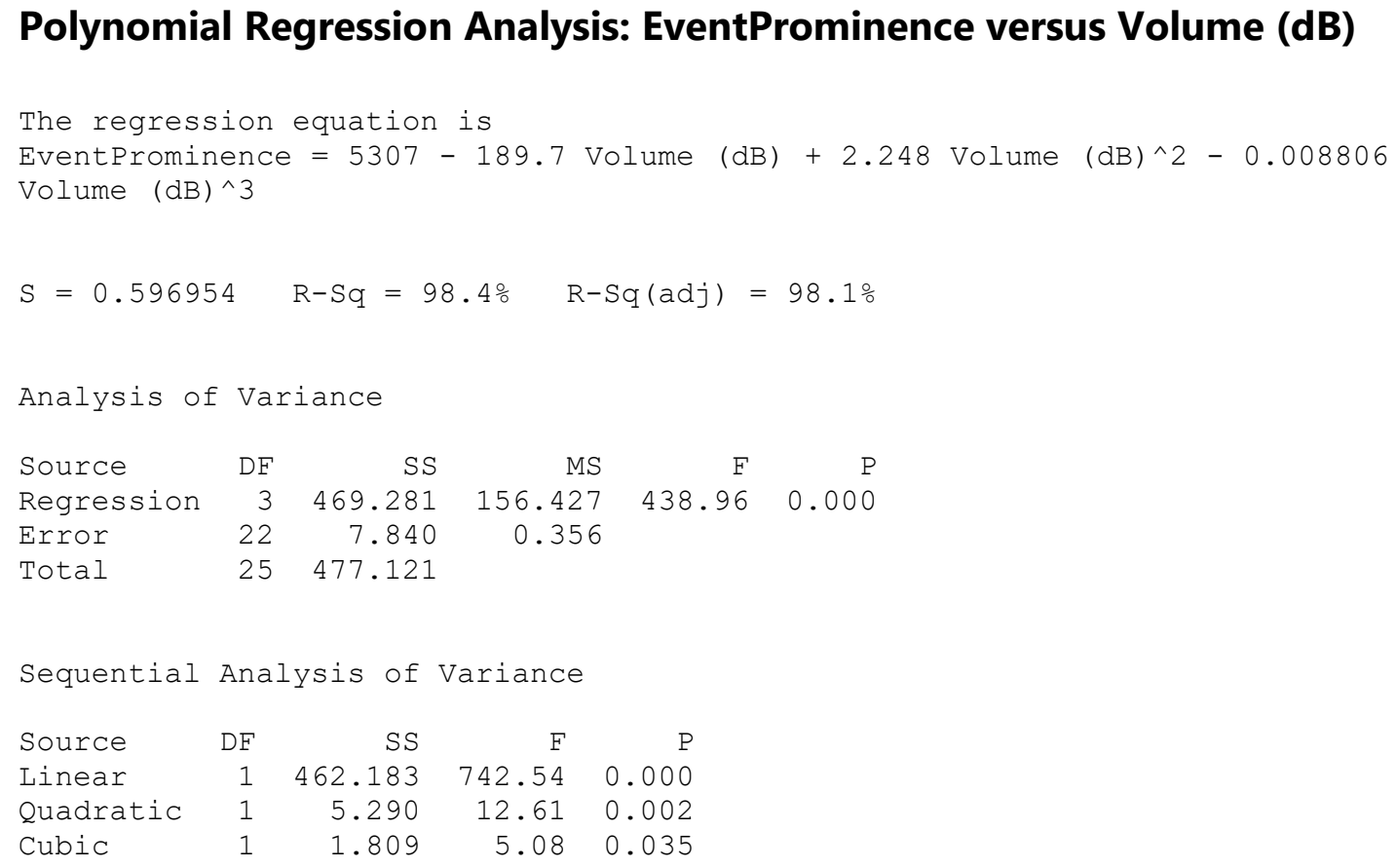

Figure 8: Regression Analysis for the DoE Showing the $R$ Squared Calculation

of the variation in EP can be explained by the factors Time and Volume, and only $1.6 \%$ error exists in the model. This gives confidence in the model and analysis.

\subsection{Pilot Study}

16 vehicles were utilised for a pilot study of the objective test with optimised parameters. These were a mixture of pass, fail, and "borderline" cars, in which operators disagreed whether they were a pass or fail. Error! Reference source not found. indicates the average of five measurements of objective data of EP on the $\mathrm{Y}$ axis with a box and whisker plot. It also indicates the subjective opinions of the operators with the colours red (fail), orange (borderline) or green (pass) for each vehicle. 


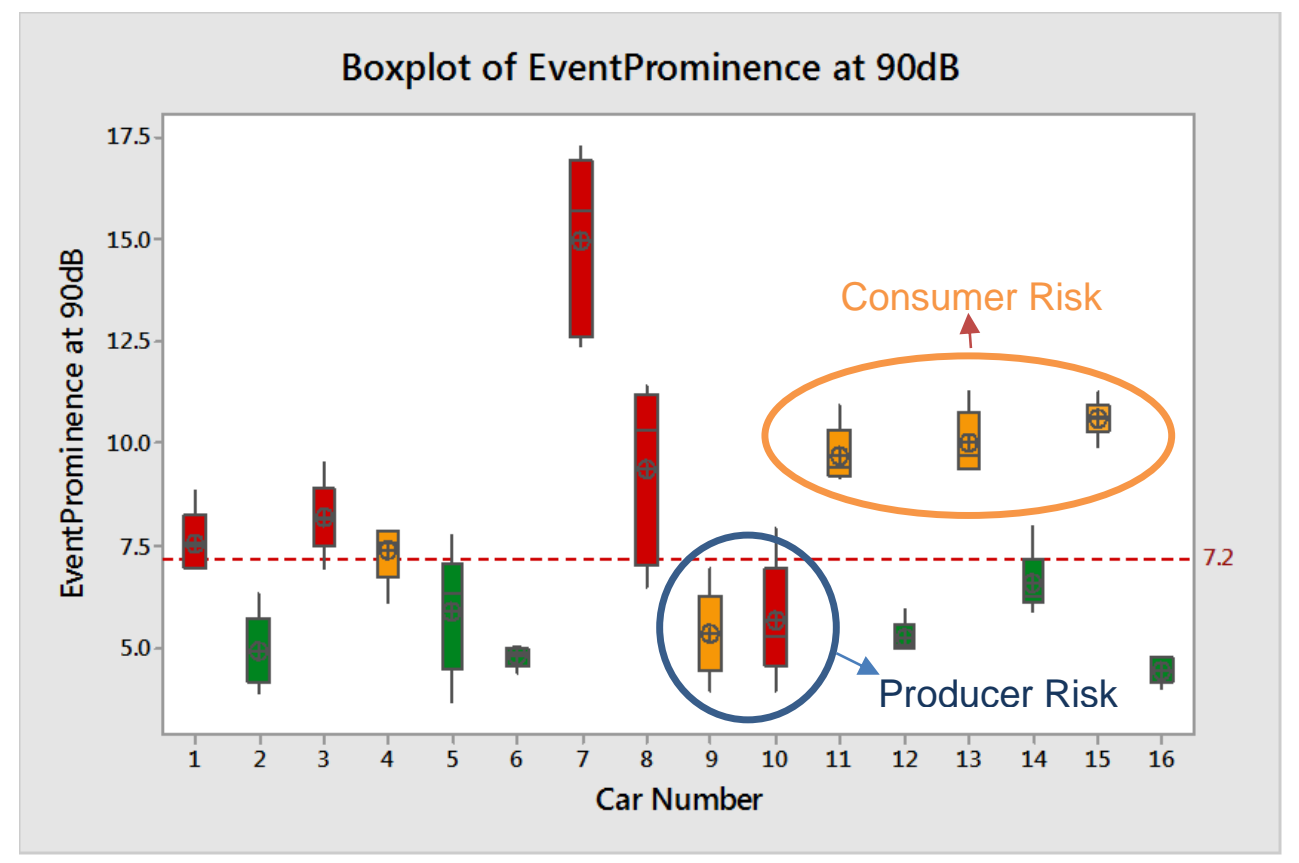

Figure 9: Boxplot of Event Prominence, showing Subjective Pass (Green), Borderline (Orange) and Fail (Red)

Figure 9 shows a clustering of objectively passed cars with a low mean EP in green. It also shows that almost all of the objectively failed cars have a larger EP. The dotted line at 7.2 is the initial estimate of a pass/ fail limit for S\&R based on the pilot study.

60 measurements were taken as part of a subjective Gauge $R \& R$. The results showed the subjective measurement test had $30 \%$ error, which is unacceptable in a measurement system [16]. Thus, it is expected that some cars will be incorrectly passed or rejected using the listening test. In Error! Reference source not found., Car 9 and 10 are clear examples of the Type I error, a Producers Risk. These are vehicles that will be reworked by the current test, but may actually be a good vehicle. Vehicles 11, 13 and 15 are examples of a Type II error, cars that could escape the plant as a pass when they do have a rattle. These cars are Consumer risks [5] [17]. Thus, the pilot study highlighted the Producer and Consumer risk for the subjective test and is further justification for the requirement for an objective test. 


\section{$8^{\text {th }}$ INTERNATIONAL CONFERENCE ON LEAN SIX SIGMA}

\section{Conclusions and Recommendations}

\subsection{Conclusions}

- The optimal settings of the objective test defined through DOE tools were a volume of $90 \mathrm{~dB}$ and a time of 5 seconds.

- $98.4 \%$ of the variation seen in the model was explained by the input factors.

- The pilot study highlighted failed cars as having a large EP and a passed car as having a lower EP. It also highlighted Producer and Consumer risk. 7.2 dB was the proposed as the initial pass/fail limit for EP.

- The subjective test had a 30\% measurement error. The objective test had a $2 \%$ measurement error.

- The business benefits of a more robust objective test were that it reduced variability, cycle time, plant escapes, rework and customer warranty.

\subsection{Recommendations}

Further investigation and a larger sample size are required to further develop the pass/fail limits. This could include building a database of "golden sample" vehicles to help characterise and improve the pass/fail criteria. The measurement system data can be utilised by engineering and quality departments. A database of rattles can be gathered which would provide a wealth of knowledge for future problem solving, for example to deep dive any systemic repeating characteristics that require a design change or operator assembly improvement. 


\section{$8^{\text {th }}$ INTERNATIONAL CONFERENCE ON LEAN SIX SIGMA}

\section{References}

[1] S. Gosavi, "Automotive Buzz, Squeak and Rattle (BSR) Detection and Prevention," SAE Technical Paper 2005-26-056, no. 26.

[2] F. Kavarana and B. Rediers, "Squeak and Rattle - State of the Art and Beyond," SAE Technical Paper 1999-01-1728, 1999.

[3] Klippel, “QC System- 100\% End Of Line Testing,” Klippel, [Online]. Available: https://www.klippel.de/our-products/qc-system.html. [Accessed 1104 2017].

[4] O. Murphy, "Designing an Objective End Of Line Assessment for Audio Induced Squeaks and Rattles" (UB14030442)," Green Belt Project Report Submitted to the University of Bradford, Bradford, 2016.

[5] O. Murphy, "Advanced Statistics for Engineering: Investigation into an Objective EndOf-Line Test for Audio Induced Squeaks and Rattles," Black Belt Project Report Submitted to the University of Bradford, Bradford, 2016.

[6] MATLAB, "MATLAB and Statistics Toolbox Release 2015b," The MathWorks Inc., Natick, Massachusetts, 2015.

[7] D. C. Montgomery, Design and analysis of experiments, Arizona: John Wiley \& Sons, 2017.

[8] L. Manning, "What's that Noise? Using FEA to Tone Down Automotive Squeaks and Rattles," Mechanical Engineering - CIME, vol. 133, no. 10, pp. 44-46, 2011.

[9] T. Lundstedt, E. Seifert and et al., "Experimental Design and Optimization," Chemometrics and intelligent laboratory systems, vol. 41, no. 1, pp. 3-40, 1998.

[10] P. K. Das and Y. Zheng, "Cumulative Formation of Response Surface and its Use in Reliability Analysis," Probabilistic Engineering Mechanics, vol. 15, no. 4, pp. 309-315, 2000. 


\section{$8^{\text {th }}$ INTERNATIONAL CONFERENCE ON LEAN SIX SIGMA}

[11] T. M. Kubiak and D. W. Benbow, The Certified Six Sigma Black Belt Handbook, Milwaukee: ASQ Quality Press, 2009, p. 299.

[12] University of Bradford , "Session 3: Multiple Regression Continued," in Design of Experiments and Response Surface Methods: ENG 4116M(BB3), Bradford, BEQIC, 2005, p. 17.

[13] J. Frost, "How to Interpret Regression Analysis Results: P-values and Coefficients," The Minitab Blog, 1st July 2013. [Online]. Available: http://blog.minitab.com/blog/adventures-in-statistics/how-to-interpret-regressionanalysis-results-p-values-and-coefficients. [Accessed 25 May 2021].

[14] P. Allison, "When Can You Safely Ignore Multicollinearity?,” September 2012. [Online]. Available: http://statisticalhorizons.com/multicollinearity. [Accessed 25 May 2021].

[15] CMU Statistics, "Lecture 19: Evaluating Predictive Models," 28 October 2009. [Online]. Available: https://www.stat.cmu.edu/ cshalizi/350/lectures/19/lecture-19.pdf. [Accessed 25 May 2021].

[16] K. M. Bower and M. E. Touchton, "Evaluating the usefulness of data by gauge repeatability and reproducibility," Elsmar, 2001.

[17] B. P. Duarte and P. M. Saraiva, “An Optimization-Based Approach for Designing Attribute Acceptance Sampling Plans," International Journal of Quality \& Reliability Management, vol. 25, no. 8, pp. 824-828, 2008.

[18] Six Sigma Academy, "Introduction to Design of Experiments (DoE)," JLR Training Material, p. 8, 2001. 